\title{
PELATIHAN PERSONAL HYGIENE TERHADAP KEMAMPUAN KELUARGA DALAM PERAWATAN DIRI PADAANAK CEREBRAL PALSY
}

\author{
Siti Fatmawati \\ STIKES ‘Aisyiyah Surakarta: w.fatma45@yahoo.co.id
}

\begin{abstract}
ABSTRAK
Latar Belakang: Gangguan kronik gerak dan postur tubuhpada anak dengan Cerebral Palsy (CP) akan menyebabkan penurunan fungsi dan ketidakmampuan untuk menjalankan aktivitas sehari-hari. Keluarga dalam hal ini adalah orang tua merupakan caregiver yang paling efektif dalam melakukan perawatan diri pada anak. Pemberdayaan kelurga difokuskan pada pelatihan perawatan diri diharapkan dapat menjadi solusi yang tepat untuk membantu keluarga dalam meningkatkan kualitas hidup anak CP.

Tujuan: Penelitian ini bertujuan untuk mengetahui pengaruh pelatihan Personal Hyigenedengan metode ceramah, diskusi, tanya jawab dan simulasi dengan audiovisual: video terhadap Kemampuan Keluarga dalam perawatan diri pada anak CP. Metode: Penelitian ini termasuk dalam jenis quasi exsperiment, dengan jumlah sampel pada kelompok yang mendapatkan pelatihan sejumlah 32 orang dan kelompok yang tidak mendapatkan pelatihan sejumlah 30 orang. Penelitian dilakukan pada bulan Maret-Juli 2016. Pengukuran dilakukan sebanyak tiga kali yaitu pretest, post test 1 , post test 2 , post test 3 . Nilai pengetahuan dan kemampuan keluarga sebelum dan sesudah pelatihan antarakedua kelompok diujikan dengan uji Mann-whitney dengan taraf signifikansi $p<0,05$.

Hasil: Peningkatan nilai rerata pengetahuan dan kemampuan keluarga dalam perawatan pada kelompok perlakuan lebih tinggi dibandingkan dengan kelompok kontrol, tetapi tidak terdapat pengaruh yang signifikan.Taraf signifikansi pengetahuan $p=0,85$ dan kemampuan Keluarga $p=0,083$. Simpulan: Peningkatan nilai rerata pengetahuan dan kemampuan keluarga pada kelompok perlakuan lebih tinggi dibandingkan kelompok kontrol tidak signifikan.
\end{abstract}

Kata Kunci: Personal Hyigene, CP, keterampilan keluarga

\section{ABSTRACT}

Background: Chronic impairment of motion and posture in children with Cerebral Palsy (CP) will lead to decreased function and inability to perform daily activities. The family in this case is the parent is the caregiver is most effective in doing self-care in children. Family empowerment focused on self-care training is expected to be the right solution to help families in improving

166 Pelatihan Personal Hygine terhadap ... 
the quality of life of CP children. Objective: This study aims to determine the effect of Personal Hygiene training with lecture, discussion, question and answer methods and simulations with audiovisual: video on Family Ability in self care in children CP. Methods: This study included in the quasi exsperiment type, with the number of samples in the group Received training of 32 people and a group that did not receive training for 30 people. The study was conducted in MarchJuly 2016. The measurement was done three times: pretest, post test 1, post test 2, post test 3. The value offamily knowledge and ability before and after training between the two groups was tested with Mann-Whitney test with significance level $P<0.05$. Result: Increased mean value of family knowledge and ability in treatment in treatment group was higher than control group, but there was no significant effect. The level of significance of knowledge $p=0.85$ and the ability of the family $p=0.083$. Conclusion: Increasing the mean value of knowledge and family ability in the treatment group was higher than the control group was not significant.

Keywords: Personal Hyigene, CP, family skills

\section{A. PENDAHULUAN}

Cerebral palsy $(\mathrm{CP})$ adalah suatu kondisi kronis yang di definisikan sebagai gangguan permanen perkembangan gerakan dan postur, yang menyebabkan keterbatasan aktivitas dan dikaitkan dengan gangguan non-progresif yang terjadi pada masa perkembangan janin atau proses kematangan otak bayi. Gangguan motorik anak CP sering disertai gangguan sensasi, persepsi, kognisi, komunikasi, dan perilaku, epilepsi dan dengan masalah muskuloskeletal. Anak-anak dengan CP mempunyai tingkat dari keparahan berbeda, maka tingkat partisipasi mereka dalam kegiatan sehari-hari akan sangat bervariasi, dan dampaknya terhadap kualitas hidup sangat tinggi (Manus et al, 2008).
World Health Organization (WHO) memperkirakan jumlah anak berkebutuhan khusus di Indonesia sekitar 7-10\% dari total jumlah anak. Menurut data susenas tahun 2003, di Indonesia terdapat 679.048 anak usia sekolah berkebutuhan khusus atau 21, 42\% dari seluruh jumlah anak berkebutuhan khusus.

Terdapatnya gangguan perkembangan yang dialami menyebabkan mereka tidak atau kurang mampu memenuhi kebutuhannya tersebut secara mandiri. Kondisi ini akan lebih sulit ketika anak CPmengalami kondisi yang komplek dimana anak tersebut tidak ada kemampuan untuk menggerakkan tangan atau kaki, kebutuhan hidup yang vital (makan dan minum) tergantung pada orang lain. Tidak dapat berkomunikasi, tidak dapat ambulasi, 


\section{GASTER Vol. XV No. 2 Agustus 2017}

kontak kejiwaan dan rasa keindahan tidak ada (Susan et al, 2010).

Gangguan kronik gerak dan postur tubuh pada anak dengan CPakan menyebabkan penurunan fungsi dan ketidakmampuan untuk menjalankan aktivitas sehari-hari. Berbagai kelainan komorbid dan rasa nyeri yang sering menyertai anak CPakan berdampak negatif terhadap kulitas hidup anak. Anak CPjuga mengalami berbagai macam masalah sosial dan emosional, seperti penolakan oleh teman, depresi, frustasi, cemas dan marah. Selain itu orang tua dari anak CPberesiko tinggi mengalami stress, kondisi keluarga yang labil, dan rendahnya kemampuan untuk bertahan dari masalah. Pengobatan dan perawatan anak CPmemberatkan dalam hal biaya, waktu dan stress dapat menjadi ancaman potensial bagi kualitas hidup anak dengan CP (Pupitasari et $a l, 2013)$.

Anak CPmembutuhkan kemampuan keluarga manual dalam aktivitas hidup keseharian yang berlangsung sepanjang perkembangan dan sesuai dengan tingkat fungsional anak. Duduk, menyeimbangkan, merangkak dan berjalan disesuaikan dengan usia, disertai dengan stimulus ekstensi protektif dan reaksi ekuilibrium. Aktivitas tangan dimulai sejak dini untuk meningkatkan fungsi motorik dan memberi anak pengalaman sensorik dan informasi tentang lingkungannya. Kemampuan anak dalam aktivitas makan dan perawatan diri mengalami kemajuan, maka pelatihan diperluas dan mencakup tugastugas lain seperti memasak atau mengetik, sesuai dengan kemampuan fungsional dan perkembangannya.Anak memerlukan bantuan dan kesabaran ketika belajar makan, berpakaian dan perawatan higiene personal (Wong, 2008).

Undang-Undang Replublik Indonesia No. 4 tahun 1997 tentang, penyandang cacat mempunyai hak dan kesempatan yang sama dalam berbagai aspek kehidupan dan penghidupan. Hak tersebut diperjelas dalam Undang-Undang No. 23 tahun 2002 tentang perlindungan anak, yang menegaskan bahwa semua anak termasuk anak penyandang cacat mempunyai hak untuk keberlangsungan hidup, tumbuh dan berkembang, perlindungan dari kekerasan dan diskriminasi serta hak untuk didengar penadapatnya. UndangUndang No. 36 tahun 2009 tentang kesehatan menyebutkan bahwa upaya pemeliharaan kesehatan penyandang cacat harus ditunjukkan untuk menjaga agar tetap hidup sehat dan produktif secara sosial, ekonomis dan 
bermartabat.Pemerintah wajib menjamin ketersediaan fasilitas pelayanan kesehatan dan memfasilitasi penyandang cacat untuk dapat tetap hidup mandiri dan produktif secara sosial dan ekonomis (Pedoman Pelayanana kesehatan anak di Sekolah Luar Biasa /SLB bagi petugas kesehatan Direktorat jendral Bina Kesejahteraan masyarakat Direktorat Bina Kesehatan Anak Kementrian RI 2010).

Keluarga dengan anak CP dalam mencari pengobatan dan perawatannya di pelayanan kesehatan sering bertemu dengan kelurga yang lain, dimana sama-sama merupakan keluarga dengan anak CP. Sering bertemunya antar keluarga dalam kesehariannya, mereka merasa tidak sendiri dalam merawat anak dengan CP. Tepatnya pada tanggal 12 Desember 2012 berdiri Wahana Keluarga Cerebral Palsy (WKCP) merupakan komunitas yang didirikan oleh orang tua yang mempunyai anak dengan CP, saat ini sudah beranggotakan sekitar 140 dan yang terdiagnosis CP sebanyak 130 anak. WKCP mempunyai kegiatan rutin setiap 2 minggu sekali dengan kegitan latihan terapi fisik, dimana terapi yang lebih di fokuskan untuk mempertahankan rentang geraknya, karena apabila tidak diterapi otot geraknya kaku, dan sebulan sekali mengadakan diskusi mengenai pengobatan dan perawatan anak dengan $\mathrm{CP}$.

Keluarga dalam hal ini adalah orang tua merupakan caregiver yang paling efektif dalam melakukan perawatan diri pada anak. Peran perawat komunitas dalam melakukan perannanya sebagai promotif dan preventif dapat memberdayakan keluarga dalam perawatan diri.Keluarga perlu ditingkatkan pengetahuan dan kemampuan keluargannya melalui program pemberdayaan kelurga. Dalam hal ini pemberdayaan kelurga difokuskan pada pelatihan perawatan diri. Metode yang digunakan dalam pelaksanaan program pemberdayaan kelurga adalah dengan menggunakan metode pelatihan (ceramah, diskusi, tanya jawab, simulasi) dan media audiovisual (video).

\section{B. BAHAN DAN METODE}

Jenis penelitian ini menggunakan penelitian quasy ekperimental dengan rancangan penelitian non randomized control pretest posttestdesign karena penelitian ini untuk mengetahui perbedaan pengetahuan, sikap, penampilan dan kemampuan keluarga dalam melakukan perawatan diri pada anak CP sebagai upaya pemberdayaan keluarga dengan 


\section{GASTER Vol. XV No. 2 Agustus 2017}

pemberian intervensi pelatihan mengenai perawatan diri pada anak CP. pengukuran dilakukan sebelum dan sesudah intervensi. Untuk pengukuran setelah intervensi post tes 1 segera setelah intervensi, post test 2 dua minggu setelah post test 1 , dan post test 3 adalah 2 minggu dari post test 2. Populasi dalam penelitian ini adalah seluruh Keluarga dengan anak Cerebral Palsy sebanyak 130 orang yang merupakan anggota WKCP di wilayah Yogyakarta.sampel yang digunakan dalam penelitian ini adalah dengan dilakukan secara purposive sampling sejumlah 67 keluarga. Varibel intervensi dalam penelitian ini adalah pelatihan perawatan diri pada anak CP. sedangkan variabel outputnya adalah pengetahuan, sikap, penampilan dan kemampuan orang tua dalam perawatan diri pada anak CP.

Instrumen yang digunakan dalam penelitian ini adalah kuesioner pengetahuan, sikap, penampilan anak CP dan kemampuan keluarga dalam melakukan perawatan pada anak CP. Lama penelitian adalah sekitar 3 bulan. Dalam mengamati pemberdayaan keluarga melalui proses dari tahu menjadi mau sehingga mampu melakukan perubahan dalam kehidupan sehari-hari sesuai dengan pendapat Sunarti (2008).

Langkah-langkah dalam pengumpulan data adalah membagi responden menjadi dua kelompok yaitu perlakuan dan kontrol, melakukan pre test pada kedua kelompok, memberikan intervensi pelatihan perawatan diri pada anak CP pada kelompok perlakukan dengan metode ceramah, diskusi, tanya jawab dan simulasi. Sedangkan pada kelompok kontrol dengan memberikan audiovisual: video perawatan diri. Dilakukan post tes 1 segera setelah intervensi dan post test 2 dua minggu atau 14 hari setelah intervensi dan post test 3 adalah 14 hari setelah post test 2 .

Data yang diperoleh kemudian diolah menggunakan kelompok perlakuan dan kelompok kontrol pada kondisi awal, post test 1 , post test 2 dan post test 3 menggunakan uji statatistik Mann-Whitney. Sedangkan untuk menganalisis perbedaan nilai tengah skor pengetahuan, sikap dan keterampilan tiap tahapan pretest, post test 1 dan post test 2 pada masing-masing kelompok digunakan uji Wilcoxon.Uji statistik dalam penelitian ini menggunakan tingkat kepercayaan 95\%. 


\section{HASIL DAN PEMBAHASAN}

Pada post test 1 dan post test 2 nilai p untuk pengetahuan sikap dan kemampuan perawatan diri menunjukkan nilai yang signifikan dengan peningkatan nilai tengah yang tidak teralalu besar. Pada post test 3, variabel pengetahuan menunjukkan nilai tidak signifikan sedangkan variabel sikap dan kemampuan perawatan diri menunjukkan nilai yang signifikan. Pada penampilan pre-post menunjukkan nilai yang signifikan dengan peningkatan nilai tengah yang tidak terlalu besar.

Berdasarkan data di bawah menunjukkan bahwa nilai tertinggi (37) dan terendah (23) untuk variabel pengetahuan didapatkan oleh keluarga yang tergabung dalam kelompok perlakuan. Nilai sikap tertinggi (83) didapatkan oleh keluarga yang tergabung kelompok perlakuan. Sedangkan nilai kemampuan keluarga tertinggi (99) didapatkan oleh keluarga yang tergabung dalam kelompok perlakuan.

Perbedaaan peningkatan pengetahuan, sikap dan keterampilan kader diidentifikasi dari selisih nilai pengetahuandan kemampuan keluarga antara pretest dengan post test 3 pada masing-masing kelompok. Peningkatan nilai masing-masing variabel dijelaskan dalam tabel di atas.
Tabel 1.1 Perbedaan Pengetahuan dan Kemampuan Keluarga dalam perawatan diri pada anak CP Bulan Mei - Juli 2016

\begin{tabular}{|c|c|c|c|}
\hline \multirow[t]{2}{*}{ Pengukuran } & \multicolumn{2}{|c|}{ Kelompok } & \multirow{2}{*}{$\underset{\text { valuc }}{\mathbf{p}}$} \\
\hline & $\begin{array}{c}\text { Perlakuan } \\
(n=32)\end{array}$ & $\begin{array}{c}\text { Kontrol } \\
(n=30)\end{array}$ & \\
\hline \multicolumn{3}{|l|}{$\begin{array}{l}\text { Pengetahuan } \\
\text { Pretest }\end{array}$} & \multirow{3}{*}{0,610} \\
\hline Mean (SD) & $30,44(2,5)$ & $30(2,2)$ & \\
\hline Median (Min-Max) & $31(23-35)$ & $30(24-34)$ & \\
\hline - $\quad$ Post test 1 & & & \multirow{3}{*}{0,006} \\
\hline Mean (SD) & $-33,44(1,9)$ & $32,23(1,6)$ & \\
\hline Median (Min-Max) & $34(29-37)$ & $32(28-35)$ & \\
\hline - $\quad$ Post test 2 & & & \multirow{3}{*}{0,001} \\
\hline Mean (SD) & $34,97(0,9)$ & $32,23(1,6)$ & \\
\hline Median (Min-Max & $35(33-36)$ & $32(28-35)$ & \\
\hline - $\quad$ Post test 3 & & & \multirow{3}{*}{0,061} \\
\hline Mean (SD) & $35,44(1,1)$ & $34,93(0,8)$ & \\
\hline Median (Min-Max) & $35,5(33-37)$ & $35(33-36)$ & \\
\hline \multicolumn{3}{|c|}{ Kemampuan } & \multirow{4}{*}{0,595} \\
\hline \multicolumn{3}{|l|}{$\begin{array}{l}\text { Keluarga } \\
\text { - Pre test } \\
\end{array}$} & \\
\hline Mean (SD) & $53,4(15,3)$ & $\begin{array}{c}51,67 \\
(14,63) \\
\end{array}$ & \\
\hline Median (Min-Max) & $54(33-91)$ & $53(33-85)$ & \\
\hline \multicolumn{3}{|c|}{ - Post test 1} & \multirow{3}{*}{0,023} \\
\hline Mean (SD) & $69,56(9,4)$ & $\begin{array}{r}61,30 \\
(14,3) \\
\end{array}$ & \\
\hline Median (Min-Max) & $71(54-98)$ & $\begin{array}{c}60,5(42- \\
89) \\
\end{array}$ & \\
\hline - $\quad$ Post test 2 & & & \multirow{3}{*}{0,001} \\
\hline Mean (SD) & $\begin{array}{l}73,50 \\
(10,3)\end{array}$ & $67,83(8,9)$ & \\
\hline Median (Min-Max) & $\begin{array}{c}72,5(54- \\
96) \\
\end{array}$ & $\begin{array}{c}69,5(47- \\
86) \\
\end{array}$ & \\
\hline \multicolumn{3}{|l|}{ - $\quad$ Post test 3} & \multirow{3}{*}{0,005} \\
\hline Mean (SD) & $80,75(8,8)$ & $\begin{array}{c}72,3 \\
(10,33) \\
\end{array}$ & \\
\hline Median (Min-Max) & $\begin{array}{c}79,5(59- \\
99)\end{array}$ & $\begin{array}{c}72,5(49- \\
96)\end{array}$ & \\
\hline
\end{tabular}

Berdasarkan tabel 4.3 nilai tengah untuk variabel pengetahuan pada kelompok perlakuan adalah 5 sedangkan pada kelompok kontrol adalah 5. Sedangkan untuk variabel kemampuan perawatan diri nilai tengahnya adalah 25,5 pada kelompok perlakuan dan 


\section{GASTER Vol. XV No. 2 Agustus 2017}

18 pada kelompok kontrol. Tabel di atas juga menunjukkan bahwa nilai pengetahuan tidak terdapat adanya kenaikan nilai.

Nilai pengetahuan keluarga sebelum menerima upaya pemberdayaan berupa pelatihan pada kelompok perlakuan dan kelompok kontrol adalah 0,610 yang berarti nilai tersebut menunjukkan tidak ada perbedaan yang signifikan pada pengetahuan awal keluarga antara kelompok perlakuan dan kelompok kontrol.Hal tersebut perlu peneliti pastikan agar peneliti mengetahui data awal pada kedua kelompok bersifat homogen atau tidak.Dengan pengetahuan awal yang sama maka peneliti dapat memastikan pengaruh dari pelatihan yang diberikan. Sebelum memberikan pelatihan, peneliti harus mengetahui informasi yang dibutuhkan oleh peserta.

Tabel 1.2Perbedaan Peningkatan Pengetahuan dan Kemampuan Keluarga dalam perawatan diri pada anak CP Bulan Mei - Juli 2016

\begin{tabular}{lcccc}
\hline \multicolumn{1}{c}{ Variabel } & N & $\begin{array}{c}\text { Mean } \\
\text { (SD) }\end{array}$ & $\begin{array}{c}\text { Median } \\
\text { (Minimum- } \\
\text { Maximum) }\end{array}$ & $\begin{array}{c}\mathbf{p} \\
\text { value }\end{array}$ \\
\hline $\begin{array}{l}\text { Pengetahuan } \\
\text { - Perlakuan }\end{array}$ & 32 & $5(2,6)$ & $5(1-13)$ & 0,85 \\
- Kontrol & 30 & $4,83(2,6)$ & $5(1-11)$ & \\
\hline $\begin{array}{l}\text { Kemampuan } \\
\text { Perawatan }\end{array}$ & & & & \\
$\begin{array}{l}\text { Diri } \\
\text { - Perlakuan }\end{array}$ & 32 & 27,34 & $25,50(-1-53)$ & 0,083 \\
& & $(13,34)$ & & \\
- Kontrol & 30 & $20,63(18,8)$ & $18(-14-63)$ & \\
\hline
\end{tabular}

Hal yang terpenting adalah peneliti harus mengetahui materi yang sesuai dengan kebutuhan peserta agar pelatihan yang dilakukan mencapai sasaran yang diinginkan. Peneliti harus memperhatikan faktor tujuan, tingkatan kognisi peserta pelatihan, harapan lembaga penyelenggara pelatihan, dan lamanya pelatihan. Hal tersebut sesuai dengan pendapat Kirkpatrick (2006), mengenai hal-hal yang perlu diperhatikan dalam merencanakan dan menerapkan program pelatihan yang efektif antara lain menentukan kebutuhan, menetapkan tujuan, menetukan isi pelatihan, memilih peserta, menetukan jadwal yang terbaik, memilih fasilitas, menentukan fasilitator yang kompeten, memilih dan menentukan alat bantu audiovisual yang tepat, mengkoordinasikan dan mengevaluasi program. Menentukan kebutuhan dan menetapkan tujuan telah peneliti lakukan saat studi pendahuluan di Wahana Keluarga Cerbral Palsy (WKCP).

Pada kelompok perlakuan dilakukan proses upaya pemberdayaan melalui pelatihan dan obervasi dari team observer. Pelatihan dilaksanakan selama 4 hari (2 hari pada kelompok pertama dan 2 hari pada kelompok kedua). Peneliti membagi keluarga dalam dua kelompok untuk memaksimalkan proses pemberian materi pelatihan. Dalam 
pelaksanaan kegiatan pelatihan pada kelompok perlakuan, peneliti menggunakan metode ceramah, diskusi, tanya jawab dan simulasi. Sedangkan pada kelompok kontrol media yang digunakan adalah media audiovisual: video.

Berdasarkan hasil penelitian yang dilakukan oleh Saleha (2009), bahwa menggunakan metode ceramah dan diskusi dalam pemberian materi akan meningkatkan pengetahuan, sikap dan perilaku seseorang. Sedangkan dengan menggunakan metode demosntrasi akan membantu keluarga agar mampu menguraikan masalah, memeragakan dan mendiskusikan masalah (Johnson, 2009). Dalam proses pemberian materi, fasilitator juga memberikan beberapa cara melakukan perawatan diri yang berkaitan dengan anak $\mathrm{CP}$. Fasilitator melakukan demonstrasi langsung dengan menggunakan boneka sehingga keluarga dapat memperhatikan secara langsung dan mencoba memperagakan. Hal ini sesuai dengan pendapat Silberman (2006), bahwa melalui metode demonstrasi dapat melibatkan peserta untuk melihat, mendengarkan dan mempraktikkan secara langsung materi yang sudah didapatkan selama proses pembelajaran.

Pada kelompok kontrol peneliti menggunakan media audiovisual: video.
Dengan melihat video secara mandiri maka keluarga akan memahami secara mandiri materi yang disampaikan dalam modul, tetapi tidak menutup kemungkinan para keluarga memiliki persepsi yang berbeda-beda terhadap materi yang dilihat. Hal ini dikarenakan keluarga tidak mendapat penyampaian materi dari petugas kesehatan yang kompeten.keluarga juga tidak mendapat kesempatan untuk melihat secara langsung praktik perawatan diri yang meliputi kebersihan diri, eliminasi, Makan dan minum seta berpakaian. Sehingga berdasarkan data di atas peningkatan pengetahuan pada kelompok perlakuan lebih tinggi dibandingkan dengan kelompok kontrol.Hal ini sesuai dengan penelitian Sukiarko (2007), bahwa dengan menggunakan metode konvensional menunjukkan peningkatan pengetahuan dan keterampilan yang lebih rendah di bandingkan dengan metode belajar berbasis masalah.

Berdasarkan data di atas menunjukkan bahwa, terdapat perbedaan yang signifikan antara sikap keluarga pada kelompok perlakuan dan kelompok kontrol sebelum mendapatkan pelatihan.

Menurut Allport dalam Notoatmodjo (2010), salah satu karakteristik dari sikap adalah adanya pendorong atau motivasi.Berdasarkan 


\section{GASTER Vol. XV No. 2 Agustus 2017}

data di atas diketahui bahwa ada peningkatan yang signifikan pada sikap orang tua sebelum dan sesudah mendapatkan pelatihan. Hal ini dapat disebabkan oleh motivasi keluarga yang masih tinggi dalam melaksanakan kegiatankegiatan keseharian terutama perawatan diri pada anak CP. Berdasarkan hasil wawancara peneliti dengan keluarga setelah berakhirnya proses pengambilan data, bahwa para keluarga merasakan senang adanya perubahan dari anak setiap waktunya. Sehingga mereka merasa termotivasi untuk melakukan tugas-tugas keesehariannya.Para keluarga juga sudah sepenuhnya mempraktikkan keterampilan yang sudah didapatkan saat pelatihan, hal tersebut dapat dilakukan disela-sela aktivitas keluarga untuk dapat menyempatkan melatih kemampuan mereka dalam melatih anak untuk mandiri.

Menurut Adrian et al (2014), bahwa pemberian materi atau pengajaran yang mengkhususkan pada keterampilan tertentu akan meningkatkan sikap. Intervensi pendidikan dapat dirancang untuk memberikan keterampilan, serta meningkatkan sikap dan pengetahuan. Dalam hal ini peneliti memberikan intervensi pendidikan dalam bentuk pelatihan yang disertakan dengan pemberian modul.
Hal ini sejalan dengan pendapat Kirkpatrick (2006) yang mendefinisikan pelatihan sebagai upaya meningkatkan pengetahuan, mengubah perilaku dan mengembangkan keterampilan. Akan tetapi hal tersebut didukung dengan hasil penelitian ini, ada peningkatan yang bermakna pada variabel sikap antara kelompok perlakuan dan kelompok kontrol.Hal tersebut menunjukkan bahwa ada perbedaan sikap yang signifikan antara kelompok yang mendapatkan pelatihan dengan modul dengan kelompok yang tidak mendapatkan pelatihan.

Media yang digunakan pada kelompok perlakuan adalah modul dan audiovisual, sedangkan pada kelompok kontrol menggunakan media audiovisual :video saja. Berdasarkan hasil penilaian peneliti terhadap respon peserta setelah mendapatkan pelatihan, didapatkan data bahwa kemampuan fasilitator dalam penggunaan media kurang maksimal sehingga pelatihan menjadi kurang menarik. Pemberian materi yang kurang menarik akan mengganggu konsentrasi dan mengurangi motivasi keluarga dalam mengikuti pelatihan. Sehingga sebaiknya perlu diantisipasi lagi dengan mempersiapkan fasilitator agar mampu membawakan materi dengan jelas dan menggunakan media yang sesuai sehingga pelatihan menjadi lebih menarik. 
Dalam menentukan sikap yang utuh, pengetahuan, pikiran, keyakinan dan emosi memegang peranan penting. Berdasarkan data di atas menunjukkan bahwa pada kelompok kontrol ada perbedaan yang signifikan antara nilai sikap pada post test 1 ke post test 2 . Hal ini berarti bahwa ada perubahan sikap yang berarti dalam jangka waktu 14 hari pada kelompok kontrol. Perubahan sikap seseorang akan terjadi seiring dengan pengalaman yang didapatkan. Pengetahuan yang meningkat dan keterampilan yang dilatih secara terus menerus akan menciptakan sikap yang lebih baik.

Pelatihan bagi keluarga tentang perawatan diri pada anak CP merupakan salah satu informasi yang dapat digunakan keluarga untuk membantu masyarakat yang memerlukan. Pengetahuan yang didapat dari pelatihan ini diharapkan dapat merubah sikap keluarga agar lebih berupaya untuk meningkatkan derajat kesehatan masyarakat terutama bagi anak dengan CP. Akan tetapi perlu dipertimbangkan mengenai lama pemberian pelatihan serta waktu yang lebih panjang untuk melakukan pengukuran post test 3 , sehingga didapatkan hasil pengukuran sikap yang lebih bermakna. Pelatihan perawatan diri pada keluarga dengan anak CP dapat meningkatkan sikap yang berguna untuk memberdayakan kelurga (orang tua) lebih mampu dalam merawat anak dengan CP. Dalam pelaksanaan pelatihan kedua kelompok menggunakan metode dan media yang berbeda walaupun keduanya sama-sama diberikan modul.Pada kelompok perlakuan menggunakan metode ceramah, diskusi dan demonstrasi dengan media modul dan audiovisual.Sedangkan pada kelompok kontrol menggunakan metode audiovisual, secara mandiri dengan media modul dan video.

Nilai tengah pada pengukuran peningkatan kemampuan keluarga dalam perawatan diri pada kelompok perlakuan sebesar 25,50 dan 18 pada kelompok kontrol dengan nilai $\mathrm{p}=0,083$ atau tidak signifikan. Dari hasil tersebut dapat disimpulkan bahwa retensi memori dan peningkatan nilai kemampuan perawatan diri pada kelompok perlakuan lebih baik dan lebih tinggi dibandingkan dengan kelompok kontrol tetapi tidak ada perbedaan yang signifikan antara peningkatan kemampuan perawatan diri pada anak antara kelompok perlakuan dan kontrol. Menurut pendapat Yang (2014), bahwa dengan menggunakan media audiovisual dan terdapatnya pendamping akan meningkatkan retensi memori yang lebih baik dibandingkan menggunakan audiovisual secara mandiri. 


\section{GASTER Vol. XV No. 2 Agustus 2017}

Pengukuran kemampuan perawatan diri dilakukan oleh para observer.Satu orang keluarga melakukan perawatan diri pada anak CP yang meliputi kebersihan diri, kebutuhan eliminasi, kebutuhan makan dan minum, serta berpakaian. Masing-masing keluarga akan menangani satu anak CP dan memberikan perawatan diri. Pelaksanaan pengukuran kemampuan perawatan diri dilakukan oleh satu orang observer untuk satu orang keluarga. Dalam lembar observasi terdapat 4 item tindakan yang harus dilakukan keluarga dalam proses pengukuran kemampuan keluarga.

Dalam proses pengukuran kemampuan keluarga dalam perawatan diri diminta untuk mempraktikkan cara melakukan perawatan diri. Pada penilaian keterampilan dilakukan pretest.Hal ini untuk mengetahui kebiasaan keluarga dalam melakukan perawatan diri sebelum dilakukan pelatihan dalam upaya pemberdayaan, sesuai dengan pendapat Sunarti (2008), bahwa bila materi pelatihan merupakan keterampilan yang sudah ada maka dilakukan pengukuran sebelum pemberian materi. Setelah dilaksanakan pelatihan, persentase keluarga yang terampil meningkat tetapi tidak mengalami peningkatan yang signifikan setelah dua minggu kemudian.
Nilai tengah pada pengukuran peningkatan penampilan anak CP pada kelompok perlakuan sebesar 5 dan 3 pada kelompok kontrol dengan nilai $\mathrm{p}=0,085$ atau tidak signifikan. Dari hasil tersebut dapat disimpulkan bahwa penampilan sebelum dan sesudah dilakukan intervensi kelompok perlakuan lebih baik dan lebih tinggi dibandingkan dengan kelompok kontrol tetapi tidak ada perbedaan yang signifikan antara peningkatan penampilan anak CP antara kelompok perlakuan dan kontrol. Menurut pendapat Wansa (2009), bahwa terdapatnya pendampingan pada keluarga akan meningkatkan kemampuan keluarga dalam melakukan perawatan pada anak.

Hal ini untuk mengetahui kebiasaan keluarga dalam melakukan perawatan diri sebelum dilakukan pelatihan dalam upaya pemberdayaan, sesuai dengan pendapat Ghazavi (2014), bahwa bila materi pelatihan merupakan keterampilan dalam upaya memberdayakan keluarga maka dilakukan pengukuran sebelum pemberian materi, berupa keadaan sebelum pemberian materi dan keadaan setelah dilaksanakan pemberian materi, persentase penampilan anak dapat meningkat tetapi tidak mengalami peningkatan yang signifikan setelah dua minggu kemudian. 
Hal tersebut berarti bahwa tidak ada perbedaan keterampilan antara kelompok yang mendapatkan pelatihan dengan kelompok yang tidak mendapatkan pelatihan.Menurut pendapat Kargar (2011), yang menyatakan bahwa Pemberdayaan yang berfokus pada keluarga setelah adanay pelatihan yang dapat meningkatkan pengetahuan dan sikap. Mempengarhui hasil yang akan tampak dari tahu menjadi mau.

\section{SIMPULAN}

Pelatihan perawatan diri dapat meningkatkan pengetahuan, dengan peningkatan pengetahuan maka dapat meningkatkan kemampuan keluarga dalam melakukan perawatan diri pada anak CP. Selanjutnya apabila pengetahuan baik, diharapkan dapat mempunyai sikap baik yang akan merubah sikap dan diharapkan ada perubahan perilaku menjadi kebiasaan, sehingga dapat meningkatkan kualitas hidup anak dengan CP. Keluarga dapat mengikuti kegiatan penyegaran atau pelatihan sejenis yang diadakan oleh pihakpihak terkait. Keluarga juga mempraktikkan pengetahuan dan keterampilan yang sudah didapatkan dalam pelatihan sehingga dapat meningkatkan kemampuan dalam melakukan perawatan diri sehingga menjadi kebiasaan sehari-hari

\section{DAFTAR PUSTAKA}

Ghazavi Z, Marzieh Sadat Minooei, Zahra Abdeyazdan, Alaleh Gheissari, 2014, Effect of family empowerment model on quality of life in children with chronic kidney diseases. Iranian Journal of Nursing and Midwifery ResearchJuly-August 2014 Vol. 19 diakses 16 September 2015

Kargar Najafi, Borhani F, Dortaj Rabari E, Sabzevari S, 2011,The Effect of Family-Centered Empowerment Model on the Mothers' Knowledge and Attitudes about Thalassemia Disorder. Iranian Journal of Pediatric Hematology oncology Vol 1. No 3.

Kirkpatrick. 2006. Evaluating Trainning Programs: The Four Levels, Third edition. San Fransisco. Barret Koehler Publishers 


\section{GASTER Vol. XV No. 2 Agustus 2017}

Manus Vicki Mc, Paul Corcoran, Ivan J Perry, 2008, Participation in everyday activities and quality of life in pre-teenage children living with cerebral palsy in South West Ireland $B M C$ Pediatrics 2008, 8:50 doi:10.1186/1471-2431-8-50

Mardiani, 2006, Faktor-Faktor Resiko Prenatal dan Perinatal Kejadian Cerebral Palsy (studi kasus di YPAC Semarang), Tesis, Program Studi Epidemologi Program Pasca Sarjana Universitas Diponegoro Semarang

Margareta, S.E, P, M, 2012, Efektivitas Self Modeling terhadap Kemampuan Mengggosok Gigi pada Anak dengan Autisme Spectrum Disorder di Karisidenan Banyumas, Tesis, Fakultas Ilmu Keperawatan Universitas Indonesia

Miller, F dan Bachrach, S 1998: cerebral palsy : a complete guide for caregiving. 3 november 2014:http;//www.amazon.com

Morton, B.G.S., Greene, W.H., Gottlieb, N.H. 1995 Introduction toHealth Education and Health Promotion. Illinois: Waveland Press, Inc.

Pedoman Pelayanana kesehatan anak di Sekolah Luar Biasa /SLB bagi petugas kesehatan Direktorat jendral Bina Kesejahteraan masyarakat Direktorat Bina Kesehatan Anak Kementrian RI 2010

Pandiangan, T., Paramastri,I., Sayoga, B. 2006 Pengaruh Pendidikan Kesehatan Reproduksi Melalui Metode Ceramah, Media Audiovisual, Ceramah Plus Audiovisual pada Pengetahuan dan Sikap Remaja SLTP. BKM, XXII (04) Desember, pp. 160-5.

Pupitasari, M.,Kusnadi Rusmil, DidaA. Gurnida, 2013, Hubungan fungsi motorik kasar dnegan kulitas Hidup anak Palsy Serebral, pustaka.unpad.ac.id diakses pada 12 Oktober 2014

Susan A. Rethlefesen, Deirde D. Ryan, Robert M.Kay, 2010, Classifocation System in Cerebal Palsy, Orthop Clin Nam 41 (2010)457-467

Sunarti, Euis, 2008, Progam Pemberdayaan dan Konseling Keluarga, Kepala Bagian Ilmu Keluarga, Departemen Ilmu Keluarga dan Konsumen Fakultas Ekologi Manusia IPB, Bandung

Suharso Darto, 2006, Kuliah Cerebral Palsy Diagnosa dan tatalaksana, dismpaiakan dalam Continuing Edfucation Ilmu Kesehatan Anak XXXVI Kapita Seleksta Ilmu Kesehatan Anak VI. Surabaya 29-30 Juli 2006 
UU No.23 Thn 2002 tentang perlindungan Anak 2002. 22 September 2014:http;//www. komisiyudisial.go.id

Wansa Saeui, Nongluk Chintanadilok, Pornsri Sriussadaporn, Wanida Sanasuttipun, 2009, The Effects of an Empowerment Program on theCompetence of Caregivers in Caring for Preschool Children with Acute Leukemia Undergoing Chemotherapy,J Nurs Sci S1 2009;27(2): $8-17$

Wong, Algreen, Arnow, Askin, Baker, Baler, U, Bown, er.al,. 2008. Nursing care of infant and Children, Eight Edition, Canada : Mosby Elsevie 